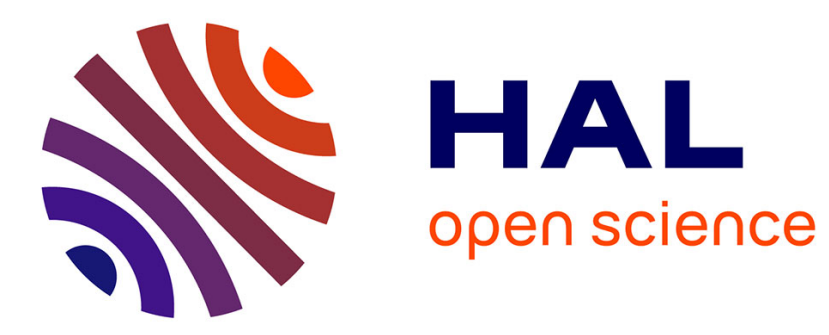

\title{
Cracking of titania nanocrystalline coatings
}

Marie Mahé, Jean-Marc Heintz, Jürgen Rödel, Peter Reynders

\section{To cite this version:}

Marie Mahé, Jean-Marc Heintz, Jürgen Rödel, Peter Reynders. Cracking of titania nanocrystalline coatings. Journal of the European Ceramic Society, 2008, 28 (10), pp.2003-2010. 10.1016/j.jeurceramsoc.2008.02.002 . hal-00280816

\section{HAL Id: hal-00280816 https://hal.science/hal-00280816}

Submitted on 23 May 2008

HAL is a multi-disciplinary open access archive for the deposit and dissemination of scientific research documents, whether they are published or not. The documents may come from teaching and research institutions in France or abroad, or from public or private research centers.
L'archive ouverte pluridisciplinaire HAL, est destinée au dépôt et à la diffusion de documents scientifiques de niveau recherche, publiés ou non, émanant des établissements d'enseignement et de recherche français ou étrangers, des laboratoires publics ou privés. 


\section{Cracking of titania nanocrystalline coatings}

\section{Marie Mahé, Jean-Marc Heintz, Jürgen Rödel and Peter Reynders}

\section{Introduction}

Titanium oxide-coated platelet-like substrates are largely used in the industry of pearlescent pigments. The most common substrate used for the precipitation of the titanium oxide layers in pigments is the muscovite mica, due to its availability. Synthetic substrates, like $\mathrm{SiO}_{2}$ platelets, $\mathrm{Al}_{2} \mathrm{O}_{3}$ platelets, glass platelets and synthetic mica have been developed during the last two decades. These substrates allow, for example, a better control of the thickness and/or of the impurities. Nevertheless, $\mathrm{TiO}_{2}$-coated natural mica remains commercially by far the most important family because of low cost of the mica substrate in comparison to synthetic substrates.[1] and [2] TiO2-coated mica studied in this work was obtained using the chloride process in which a $\mathrm{TiOCl} 2$ solution is slowly added to a mica platelet suspension at low $\mathrm{pH}$ and temperatures of $60-90^{\circ} \mathrm{C}$. The synthesis of $\mathrm{TiO}_{2}$-coated platelet-like substrates produced by Merck has already been optimised in terms of $\mathrm{TiO}_{2}$ precipitation, lustre and chroma. Nevertheless, the presence of cracks can still be observed at the surface of some of the pigments. In order to continuously improve the quality of the pigments, crack formation at the surface of inorganic pigments needs to be understood.

Cracking of inorganic films has repeatedly been reported in the literature.[3], [4], [5], [6], [7], [8], [9], [10], [11], [12], [13] and [14] Depending on the systems studied, several reasons have been proposed for crack formation. The drying of porous material, like sol-gel bodies[3], [4], [8] and [13] or granular ceramics[5], [6], [7], [9], [10], [11], [12] and [14] is often seen as a decisive step for the appearance of cracks at the surface of these materials. In these cases, drying stresses develop which are linked to the tension forces that exist in the liquid inside the pores of the drying body. Crack formation is also reported to occur during sintering of ceramic films for cases with differential sintering leading to strain incompatibilities.[5], [6], [7] and [11] During sintering, cracks favourably develop from intrinsic defects. Finally, problems of crack formation and decohesion can also develop during cooling of annealed ceramic films deposited on a substrate due to differences between the thermal expansion coefficients of the substrate and the coated film.[15] and [16] An improved understanding of the cracking of $\mathrm{TiO}_{2}$ nano-layers deposited on platelet-like substrates is presented in this study. The effects of the drying step and the calcination step on cracking are treated. Moreover, the influence of layer thickness as well as of the underlying substrate has been examined, with respect to their acido-basicity, crystallinity and roughness. 


\section{Experimental}

\subsection{Synthesis of the samples}

Titanium oxide layers were deposited on different platelet-like substrates via an aqueous liquid deposition process (LDP).[1], [2] and [17] It corresponds to controlled precipitation, at low pH ( 2 ), of titanium chloride within an aqueous suspension containing the substrates. $\mathrm{The} \mathrm{TiO}_{2}$ rutile structure leads to a higher refractive index than the $\mathrm{TiO}_{2}$ anatase structure. ${ }^{2}$ Therefore, a process has been developed at Merck to create $\mathrm{a} \mathrm{TiO}_{2}$ rutile layer on mica by precipitating first a very thin $\mathrm{SnO}_{2}$ layer on the substrate, which acts as a template for the $\mathrm{TiO}_{2}$ rutile. The preparation of the samples used in this publication has been described in the literature. ${ }^{17}$ The thickness of the $\mathrm{TiO}_{2}$ layers can be accurately controlled ( $\pm 5 \mathrm{~nm}$ ) by varying the amount of titanium chloride solution. The precipitates were filtered off, washed completely with deionized water and dried at $110^{\circ} \mathrm{C}$ for $12 \mathrm{~h}$. The dried pigments were then sintered at $850^{\circ} \mathrm{C}$ for $30 \mathrm{~min}$.

The $\mathrm{TiO}_{2}$ layer thickness deposited on the substrates were equal to $60 \mathrm{~nm}, 140 \mathrm{~nm}$ and $300 \mathrm{~nm}$ after sintering. Natural mica, $\mathrm{SiO}_{2}$ platelets and $\mathrm{Al}_{2} \mathrm{O}_{3}$ platelets were utilized as substrates. To describe the samples studied in this work, the following type of notation will be used: "Ti-140-mica" with "Ti" for TiO2 layer, "140" for $\mathrm{TiO}_{2}$-thickness layer equal to $140 \mathrm{~nm}$ after sintering and "mica" for the substrate used.

\subsection{Substrates}

The titanium oxide layers were precipitated on three different substrates: mica platelets (Merck, diameter 10-50 $\mu \mathrm{m}$, thickness range 300-800 nm, mean thickness $400 \mathrm{~nm}$ ), $\mathrm{SiO}_{2}$ platelets (Merck, diameter 10-50 $\mu \mathrm{m}$, thickness $450 \pm 10 \mathrm{~nm}$ ) and $\mathrm{Al}_{2} \mathrm{O}_{3}$ platelets (Merck, diameter 10-50 $\mu \mathrm{m}$, thickness $200 \pm 10 \mathrm{~nm}$ ). The mica employed is the natural dioctahedral muscovite $\mathrm{KAl}_{2}\left[\mathrm{AlSi}_{3} \mathrm{O}_{10}\right]$ $(\mathrm{OH})_{2} \cdot{ }^{18}$ The surfaces of the mica muscovite platelets are oriented along the $\left(\begin{array}{lll}0 & 0 & 1\end{array}\right)$ plane. ${ }^{19}$ The synthetic $\mathrm{SiO}_{2}$ platelets are produced by a web-coating process. ${ }^{20}$ These substrates are amorphous. $\mathrm{Al}_{2} \mathrm{O}_{3}$ platelets ( $*-\mathrm{Al}_{2} \mathrm{O}_{3}$, corundum) were produced using a controlled crystal growth process in molten sodium sulfate. ${ }^{20}$ The surface of the platelets is preferentially orientated according to the $\left(\begin{array}{lll}0 & 0 & 1\end{array}\right)$ plane of $*-\mathrm{Al}_{2} \mathrm{O}_{3}$ corundum. There is no correlation between the lattice parameters of mica or $\mathrm{Al}_{2} \mathrm{O}_{3}$ platelets (corundum) with the lattice parameters of $\mathrm{SnO}_{2}$ and $\mathrm{TiO}_{2}$ rutile or anatase. The points of zero charge (PZC) values, given in the literature, for the oxides constituting the substrates are the following: $\mathrm{PZC}_{\mathrm{SiO}_{2}} 2$ and $\mathrm{PZC}_{\mathrm{Al} 203\left(\begin{array}{ll}0 & 1\end{array}\right) \text { 5-6.[18] }}$ and [21] Since the main plane developed at the surface of mica is close to $\mathrm{SiO}_{2}$, the PZC of mica can be considered close to the $\mathrm{SiO}_{2}$ value. Most of the experiments have been carried out with the three previously quoted substrates: natural mica, $\mathrm{SiO}_{2}$ and $\mathrm{Al}_{2} \mathrm{O}_{3}$ platelets. Nevertheless, some experiments have been performed using synthetic mica and glass platelets. In fact, the surfaces of $\mathrm{SiO}_{2}, \mathrm{Al}_{2} \mathrm{O}_{3}$ and glass platelets are 
smoother than those of natural and synthetic mica. Also, the chemical nature of synthetic and natural mica (respectively fluorophlogopite and muscovite) is different.

\subsection{Characterization of pigments}

The layers consist of oxide particles, which are called grains throughout this publication to make a clear distinction from the whole pigment particles themselves that consist of these films attached to substrates. In a given sample, not all pigment particles contain cracks. Therefore, the average percentage of pigment particles exhibiting cracks in a sample has been determined, using light microscopy. For ease of reading, the term "crack percentage" is used in the following instead of "average percentage of pigment particles". Micrographs of the samples were taken using an Eclipse ME 600 (Nikon $\mathrm{GmbH}$ ) under reflection conditions. It has also been used to determine the evolution of the cracks between the drying and the sintering steps. For this purpose, dried pigment particles were deposited on a sapphire holder on which markers had been inscribed. The dried particles were observed through the optical microscope; then the system composed of the dried particles on the sapphire holder was sintered at $850^{\circ} \mathrm{C}$ for $30 \mathrm{~min}$. Thanks to the markers on the sapphire holder, the pigments previously observed in their dried state were identified and characterized after sintering.

The morphology of the $\mathrm{TiO}_{2}$ layers and of the substrates was studied by scanning electron microscopy (SEM) (LEO 1530 Gemini). SEM was also used to measure the layer thickness on micrographs of fractured pigments. The pigments were mixed with a lacquer and dried. The lacquer, containing the pigments, was then broken in such a way that some of the particles were also fractured which allowed the thickness of the coating film to be measured.

The Brunauer-Emmett-Teller (BET) specific surface areas and the pore volumes were measured using a Micromeritics ASAP 2400 apparatus with nitrogen at $77 \mathrm{~K}$. Assuming that the surface area of the substrates is negligible and that the $\mathrm{TiO}_{2}$ grains attached to them are spherical, the particle size GBET of dried $\mathrm{TiO}_{2}$ layers was evaluated. (The specific area of mica, $\mathrm{SiO}_{2}$ platelets and $\mathrm{Al}_{2} \mathrm{O}_{3}$ platelets are $2.8,3.05$, and $1.8-3.0 \mathrm{~m} 2 / \mathrm{g}$, respectively.) The weight percentage of $\mathrm{TiO}_{2}$ in the pigments is taken into account for determination of the grain size:

$$
G_{\mathrm{BET}}(\mathrm{nm})=\frac{6000 f_{\mathrm{TiO}_{2}}}{S_{\mathrm{BET}} \times \rho_{\mathrm{TiO}}}
$$

Here $\mathrm{fTiO}_{2}$ is the $\mathrm{TiO}_{2}$ weight oxide fraction, SBET is the BET surface area $(\mathrm{m} 2 / \mathrm{g})$ and $\rho \mathrm{TiO} 2$ is the theoretical density of titanium oxide $(4.26 \mathrm{~g} / \mathrm{cm} 3$ (for rutile) and $3.85 \mathrm{~g} / \mathrm{cm} 3$ (for anatase)). The relative densities prel of the $\mathrm{TiO}_{2}$ layers were also deduced from nitrogen adsorption measurements. Finally, the average pore radius $\bar{r}_{\mathrm{p}}$ of the sample is also calculated from the nitrogen adsorption analyses according to the following formula (Eq. (1)): 
(1)

$$
\bar{r}_{\mathrm{p}}=\frac{2 \times V_{\mathrm{tot}}}{S_{\mathrm{BET}}}
$$

The average pore radius $\bar{r}_{\mathrm{p}}$ is different from the most frequent pore size deduced from the pore size distribution but provides a rough estimate of the pore size in a sample.

X-ray analyses (Bruker AXS D5000 $\theta / \theta$ diffractometer) were carried out to determine the crystallite size of the titanium oxide precipitated on the substrates. The radiation used was $\mathrm{Cu} \mathrm{K} * 1$. The crystallite size (DXRD) was estimated from the full width at half-maximum of diffraction peaks using the Scherer equation (Eq. (2)):

(2)

$$
D_{\mathrm{XRD}}=\frac{0.9 \lambda \mathrm{Cu} K \alpha_{1}}{\sqrt{B^{2}-b^{2}} \cos \theta}
$$

Here $\theta$ is the scattering angle, $B$ is the peak width at half height and $b$ the peak width at half height of the reference substance $\left(\mathrm{LaB}_{6}\right)$. The wavelength of the $X$-ray is $\lambda \mathrm{Cu} \mathrm{Ka1}=0.1541 \mathrm{~nm}$.

Pycnometry analyses were performed in ethanol at $20^{\circ} \mathrm{C}$ for $\mathrm{SiO}_{2}$ platelets dried at $110{ }^{\circ} \mathrm{C}$, and sintered at 600 or $850^{\circ} \mathrm{C}$.

The AFM results reported in this paper were obtained in air at room temperature using a Park Scientific Instruments Autoprobe CP scanning probe microscope (SPM) operating in the non-contact mode.

\section{Results}

\subsection{Substrate morphology}

SEM observations show that surfaces both from natural and synthetic mica platelets exhibit defects (Fig. 1). The presence of step-like defects at their surface is related to the easy cleavability of mica. These defects can be detected at the surface of natural mica as well as synthetic mica. According to the SEM micrographs, $\mathrm{SiO}_{2}, \mathrm{Al}_{2} \mathrm{O}_{3}$ and glass platelets are smoother.

AFM images were recorded on three small defect-free areas (edge length about 2-5 $\mu \mathrm{m}$ ) that were selected from different regions. For each substrate, two platelets were analysed and the average roughness determined. The synthetic mica exhibits a rather high average roughness ( $9 \mathrm{~nm})$ in contrast to natural mica where it is rather low $(\sim 1 \mathrm{~nm})$. The average roughness of glass platelets $(\sim 5 \mathrm{~nm})$ and $\mathrm{SiO}_{2}$ platelets $(.4 \mathrm{~nm})$ is smaller than the value for synthetic mica but larger than the average roughness of natural mica. Finally, the average roughness of the $\mathrm{Al}_{2} \mathrm{O}_{3}$ surface is very small $(<1 \mathrm{~nm})$. 
Mica substrate surfaces exhibit steps, especially close to the edges of the mica particle. The height of the steps of synthetic and natural mica was determined: average values for these two types of mica are around 20-100 nm (Fig. 2). Occasionally, rare step-like defects on $\mathrm{Al}_{2} \mathrm{O}_{3}$ or $\mathrm{SiO}_{2}$ can also be found.

\subsection{Thermal evolution of the substrates}

Mica and alumina platelets, which are subjected to temperatures higher than $850{ }^{\circ} \mathrm{C}$ before their use in the LDP process, do not exhibit any significant modification as regards to their size and mass during the sintering of the pigments. In contrast, pigments based on $\mathrm{SiO}_{2}$ can shrink in the lateral direction during the heat treatment. Optical microscopy was employed to determine the in-plane shrinkage of non-coated $\mathrm{SiO}_{2}$ platelets during the sintering process. Between 110 and $850{ }^{\circ} \mathrm{C}$, shrinkage is about $6-8 \%$. These values are close to the ones that have been measured on pigment particles $(6 \%)$.

The volume shrinkage of $\mathrm{SiO}_{2}$ platelets was also investigated using pycnometry analyses in ethanol. $\mathrm{SiO}_{2}$ platelets dried at $110^{\circ} \mathrm{C}$ or sintered at $600{ }^{\circ} \mathrm{C}$ or $850{ }^{\circ} \mathrm{C}$ were measured. The densities deduced from these experiments and the corresponding volume shrinkages are provided in Table 1. Densification occurs mostly between 600 and $850^{\circ} \mathrm{C}$. Moreover, qualitative agreement is obtained between 2D observations and pycnometry analyses since the final experimental value of the volume shrinkage $(\Delta \mathrm{V} / \mathrm{V}=14 \%)$ is about the same order of magnitude of the value that can be calculated from the linear shrinkage determined by optical microscopy $(\Delta \mathrm{V} / \mathrm{V}=(1-\Delta \mathrm{l} / \mathrm{I}) 3 \sim 17 \%)$.

A thermogravimetric analysis (TGA) of SiO2 platelets previously dried at $110{ }^{\circ} \mathrm{C}$ was also performed from 25 to $900{ }^{\circ} \mathrm{C}$. The weight loss is equal to $7.3 \%$ at $700{ }^{\circ} \mathrm{C}$. About $3.8 \%$ of the weight loss occurs before $200{ }^{\circ} \mathrm{C}$ and $3.4 \%$ of the weight is lost from 200 to $700{ }^{\circ} \mathrm{C}$. The major weight loss occurs before $600{ }^{\circ} \mathrm{C}$, before the volume shrinkage of $\mathrm{SiO}_{2}$ platelets takes place.

\subsection{Pigment particles}

The pigments obtained after the LPD process and drying are presented in Fig. 3. A pigment sample is composed of thousands of pigment particles. The diameter of a pigment particle is about 10$50 \mu \mathrm{m}$ and $\mathrm{TiO}_{2}$ layer thicknesses are about 50-300 nm.

\section{4. $\mathrm{TiO}_{2}$ layers}

Pore and grain sizes from the different dried $\mathrm{TiO}_{2}$ layers are reported in Table 2. The average pore radius $\bar{r}_{\mathrm{p}}$ is about $2 \mathrm{~nm}$. This value is quite consistent with a theoretical radius of a pore (rth) surrounded by 3 crystallites of radius $R$, that can be calculated from the following equation 14 : $(\mathrm{R}+\mathrm{rth}) \cos 30^{\circ}=\mathrm{R}$. 
In our case, $\mathrm{R}$ is taken from BET measurements: $\mathrm{R}=\mathrm{GBET} / 2$ and $10<\mathrm{GBET}<30 \mathrm{~nm}$, providing a theoretical pore radius ranging from 0.8 to $2.3 \mathrm{~nm}$.

$\mathrm{TiO}_{2}$ grains are confirmed as monocrystalline since values given by BET and X-ray diffraction measurements are very similar. The grain size seems to increase with layer thickness according to both types of measurements. 26

The SEM micrographs of the microstructure of dried $\mathrm{TiO}_{2}$ layers in $\mathrm{Ti}-140-\mathrm{Al}_{2} \mathrm{O}_{3}$ and in $\mathrm{Ti}-300-\mathrm{Al}_{2} \mathrm{O}_{3}$ demonstrate that the $\mathrm{TiO}_{2}$ granular layer is precipitated homogeneously and regularly on the substrate (Fig. 4). The film thickness in a given pigment remains constant. Grain size of the dried layers is in the nanometric range as shown by BET and XRD analyses.

\subsection{Crack percentage}

As already mentioned, the preparation of inorganic layer-substrate pigments is composed of several steps. After precipitation, the pigment particles are dried and then sintered at $850{ }^{\circ} \mathrm{C}$. The presence of cracks is detected after the drying step (Fig. 5), although the cracks are then barely visible.

After sintering, cracks are more easily detected with light microscopy or SEM and the crack percentage was determined. In most cases, several samples corresponding to the same type of pigments have been studied to check the reproducibility of the results. The influence of different parameters (layer thickness, substrate nature, precipitation conditions) on crack percentage after sintering is reported in Table 3. It can be noted that there is a critical thickness beyond which the crack percentage increases (see Ti-60-mica and Ti-140-mica or Ti-140- $\mathrm{Al}_{2} \mathrm{O}_{3}$ and $\mathrm{Ti}-300-\mathrm{Al}_{2} \mathrm{O}_{3}$ ). This critical thickness is smaller when $\mathrm{TiO}_{2}$ layers are precipitated on mica (between 60 and $140 \mathrm{~nm}$ ) than when they are precipitated on $\mathrm{Al}_{2} \mathrm{O}_{3}$ and $\mathrm{SiO}_{2}$ platelets ( $>140 \mathrm{~nm}$ ). 3.6. Crack evolution during sintering of pigments

The evolution of cracks between the drying and the sintering steps has been analysed for the different pigments. Examples of mica based pigments are presented in Fig. 6. Cracks present at the surface of sintered pigment particles are more visible than cracks present at the surface of as-dried pigments. Nevertheless, the crack percentage of dried and sintered samples is about the same, which indicates that cracks are formed during the drying step.

Moreover, SEM micrographs performed on the same area of a cracked pigment particle show that the crack opening displacement within dried $\mathrm{TiO}_{2}$ layers increases during the sintering process (Fig. 7).

As shown in Table 3 and Fig. 5, the Ti-300- $\mathrm{Al}_{2} \mathrm{O}_{3}$ pigment also exhibits cracking problems. The evolution of cracks between the drying and the sintering steps has been observed for several $\mathrm{Ti}-300-\mathrm{Al}_{2} \mathrm{O}_{3}$ pigment particles. Again, cracks at the surface of sintered pigment particles are more 
visible than cracks present at the surface of dried pigments. Some cracks are widening but the crack percentage of dried and sintered samples remains similar. The same conclusion as for mica based pigments can then be drawn: the main cracks are formed during the drying step. In contrast, the case of pigments based on silica substrates is different from the other substrates. For example, the crack percentage in $\mathrm{Ti}-140-\mathrm{SiO}_{2}$ samples is very low. However, a very small amount of cracks can be detected in the dried sample and the evolution of these cracks during sintering can be observed using light microscopy. Cracks initiated during the drying step were either eliminated or rendered less visible after sintering.

\section{Discussion}

\subsection{Cracking during drying}

As has been pointed out in the results, cracking of $\mathrm{TiO}_{2}$ layers can be attributed to the drying step of the pigments. The drying of $\mathrm{TiO}_{2}$ layers is performed in this study at $110{ }^{\circ} \mathrm{C}$. At this temperature, the thermal expansion of the substrates should be limited and the difference in thermal expansion between the film and the substrate should not cause crack formation. To confirm this hypothesis, a Ti-140-mica sample was dried at room temperature in a desiccator. Its crack percentage was found comparable to a sample dried in the oven at $110^{\circ} \mathrm{C}$. Thus, it can be concluded that the difference in thermal expansion between the $\mathrm{TiO}_{2}$ layer and mica substrate is not governing the cracking of $\mathrm{TiO}_{2}$ layers.

The influence of the drying step on the cracking of inorganic materials like granular ceramics or gels[8], [22], [23], [24] and [25] has been mainly linked to the presence of the liquid in the pores during the drying of the body. At the onset of drying, water evaporates from the pores at the surface of the material. This leads to the substitution of a solid/liquid interface by a solid/vapour interface, if the water is not replenished from the interior of the body. To prevent exposure of the solid phase, the meniscus of the liquid adopts a curved liquid/vapour interface. A capillary pressure $(\Delta \mathrm{P})$ develops across the curved interface liquid/gas and reaches its maximum value $(\Delta \mathrm{PM})$ when the radius of the meniscus is small enough to fit into the pores. This leads to tension in the liquid, balanced by compressive forces in the solid phase which causes the network to shrink. The maximum value of the capillary pressure $(\Delta \mathrm{PM})$, which corresponds to the maximum of the drying stress, is given by Eq. (3)8:

$$
\Delta P_{\mathrm{M}}=\frac{2 \gamma_{\mathrm{LV}} \cos \theta}{a}
$$

Here YLV is the liquid/vapour interfacial energy, $\theta$ is the contact angle between the liquid and the solid phase, and $a$ is the pore radius. 
In Eq. (3), pores are considered cylindrical and the pore radius (a) is the radius of the pores in the drying material when $\triangle \mathrm{PM}$ is reached. The exact value of a for the present products was not precisely determined since the layer characterization was performed after the drying and not during the drying. Nevertheless, a can be approximated by $\bar{r}_{\mathrm{p}}$, the average pore radius deduced from the nitrogen adsorption measurements since most of the shrinkage occurs before $\triangle \mathrm{PM}$ is reached. 8 Then, for $\cos \theta \approx 1, \mathrm{YLV}=7 \times 10-3 \mathrm{~J} \mathrm{~m}-2$ (surface tension of water) and $a \approx \bar{r}_{\mathrm{p}} \approx 2 \mathrm{~nm}$, the maximal capillary pressure $\triangle \mathrm{PM}$ is about $70 \mathrm{MPa}$. It is possible to show with this simple estimation of $\triangle \mathrm{PM}$ that there is a significant capillary tension in the liquid at the critical point. The capillary pressure $\Delta \mathrm{P}$ causes contraction of the solid phase during drying. When the solid phase is a film deposited on a rigid substrate like a gel film[24] and [25] or a granular ceramic film,[9], [10], [12] and [13] the contraction of the film imposes compressive stresses on the substrate and corresponding tensile stresses in the film. These can lead to the initiation of cracks at stress concentrators like pores.

\subsection{Cracking during sintering}

Sintering does not promote cracking in mica and alumina based pigments. Specifically, sintering of constrained Ti-140-mica and $\mathrm{Ti}-300-\mathrm{Al}_{2} \mathrm{O}_{3}$ films leads to a widening of the cracks and also to a higher densification near the crack faces since there are no geometrical constraints close to the cracks. ${ }^{26}$

The sintering behaviour of the $\mathrm{SiO}_{2}$ platelets leads to a different scenario: for the $\mathrm{Ti}-140-\mathrm{SiO}_{2}$ pigment, the occasional cracks formed during drying are eliminated or partially healed during the sintering step. The increase in density of the amorphous SiO2 platelets from 1.770 to $2.019 \mathrm{~g} \mathrm{~cm}-3$ between 600 and $850{ }^{\circ} \mathrm{C}$ is attributed to a real densification. This increase in density is not correlated to the $\mathrm{SiO}_{2}$ platelet weight loss, which occurs mainly between 25 and $600{ }^{\circ} \mathrm{C}$. The weight loss is first due to water removal from the surface of the $\mathrm{SiO}_{2}$ platelets (until $200{ }^{\circ} \mathrm{C}$ ) and then due to the release of water resulting from the dehydroxylation of silanol groups on the surface of $\mathrm{SiO}_{2}$ platelets. The obtained density at $850^{\circ} \mathrm{C}(2.019 \mathrm{~g} \mathrm{~cm}-3)$ is in agreement with values found in the literature for amorphous silica of around $2.200 \mathrm{~g} \mathrm{~cm}-3.27$ Therefore, the densification of $\mathrm{SiO}_{2}$ substrates leads to shrinkage of the platelets, which can lead to partial or complete crack healing.28

\subsection{Influence of layer thickness on the cracking of dried $\mathrm{TiO}_{2}$ layers}

Cracking behaviour is observed to depend on layer thickness: for the same substrate, cracking of Tioz layers increases with the thickness of the layer (Table 3 and Fig. 5).

According to linear elastic fracture mechanics, a constrained film, subject to stress, will crack when the strain energy released in the process exceeds the energy required to form the crack.[29] and [30] For a film and a substrate having the same elastic moduli, a critical thickness for film cracking 
(hf) can be expressed at a given level of tensile stress ( $\sigma x)$ by the following equation Eq. (4)30:

(4)

$$
h_{\mathrm{f}}=\frac{2}{\pi \cdot c_{\mathrm{e}}^{2}} \frac{\Gamma_{\mathrm{f}} E_{\mathrm{f}}}{\sigma_{\mathrm{x}}^{2}}
$$

Here ce is a dimensionless constant (close to 1), Ef is the elastic modulus of the film and $\mathrm{Cf}$ is the energy required to form two new crack surfaces per unit area.

In our case, it is not possible to calculate precisely this critical cracking thickness since Ef and $\Gamma f$ are not known for such granular nanometric films. However, due to the nanometric character of the microstructure, the development of high drying stresses in these nanocrystalline films is very likely (see the high value of capillary pressure estimated in Section 4.1). It can account for a submicrometer critical cracking thickness as it is often observed in the case of granular films obtained through sol-gel processes $(<0.1 \mu \mathrm{m}) .[31]$, [32] and [33] Experimentally, the critical cracking thicknesses of the studied films fit reasonably well with this analysis. They can be estimated to be of the order of $100 \mathrm{~nm}$ when $\mathrm{TiO}_{2}$ is deposited on mica and $>140 \mathrm{~nm}$ when deposited on alumina or silica (Table 3 ).

\subsection{Influence of the substrate on the cracking of dried $\mathrm{TiO}_{2}$ layers}

Considering Ti-140-mica, $\mathrm{Ti}-140-\mathrm{Al}_{2} \mathrm{O}_{3}$ and $\mathrm{Ti}-140-\mathrm{SiO}_{2}$ green pigments, the $\mathrm{TiO}_{2}$ layers exhibit the same properties with respect to porosity, grain size and layer thickness but the cracking behaviour of these layers differs. Therefore, the substrates on which the layers are precipitated exert an influence on the cracking of the $\mathrm{TiO}_{2}$ layers.

As already mentioned, the difference in thermal expansion between the different substrates is not the main cause of the difference in cracking behaviour of $\mathrm{TiO}_{2}$ layers since cracking occurs at relatively low temperature $\left(110^{\circ} \mathrm{C}\right)$.

The surface charge and the surface structure of the different substrates also cannot explain the different cracking behaviour of the TiO2 layers. In the precipitation conditions $(\mathrm{pH}<2)$, all substrates present a relatively positive surface charge $(\mathrm{pH}<\mathrm{PZC})$, leading to the same $\mathrm{TiO}_{2}$ precipitation.

Further, no correlation could be established between the substrate lattice parameters and the $\mathrm{SnO}_{2}$ ( $\equiv \mathrm{TiO}_{2}$ rutile) lattice parameters, so that template effects are not expected. Besides, $\mathrm{TiO}_{2}$ anatase layers were precipitated on different substrates, and their cracking behaviour depends on the underlying substrates in the same way as for $\mathrm{TiO}_{2}$ rutile layers.

The roughness of the different substrates should be considered in more detail since this parameter can control the adhesion of the film on the substrate. 
The values obtained for the roughness of the different substrates are, however, not conclusive. $140 \mathrm{~nm} \mathrm{TiO}_{2}$ layers only exhibit cracks when deposited on synthetic or natural mica, which exhibit an average roughness of either $9 \mathrm{~nm}$ or $1 \mathrm{~nm}$, respectively. The average roughness of glass platelets $(5 \mathrm{~nm})$ and $\mathrm{SiO}_{2}$ platelets $(4 \mathrm{~nm})$ is smaller than the average roughness of synthetic mica and larger than the average roughness of natural mica. Finally, the average roughness of $\mathrm{Al}_{2} \mathrm{O}_{3}$ is very small $(<1 \mathrm{~nm})$. However, a common feature of natural and synthetic mica is the steps present at the surface of the platelets.

A Finite Element Model (FEM)-stress simulation was performed to simulate the development of stresses in a drying layer deposited on a rigid substrate containing steps. For this model, constrained film shrinkage was simulated using the strain mismatch which occurs when cooling from an increased temperature with different thermal expansion coefficient for film and substrate. The temperature difference and the thermal expansion mismatch were chosen to match the strain incompatibility during drying. Mechanical and geometrical parameters are provided in Fig. 8 . The results of the computation are provided with a focus on the effect of surface inhomogeneities on stress distribution (Fig. 9). The FEM simulation confirms that there is an increase of the stress when step-like defects are present at the surface of the substrate. The increase of the stress occurs in the vicinity of the steps and extends to a distance of the order of the step height. In some cases, cracks are experimentally observed along the steps at a distance that fits reasonably with the simulation. In other cases, no clear correlation between cracking and steps could be observed. However, this FEM simulation was quite simple and therefore too limited to simulate precisely what happens in a polycrystalline $\mathrm{TiO}_{2}$ layer. For example, the different powder packing around steps and the attendant effect on local fracture energy cannot be avoided and could not be taken into account.

\section{Conclusion}

Cracking in thin nanocrystalline titania films deposited on different substrates has been shown to develop during drying. The subsequent sintering step leads to an increase of the crack opening displacement for dense substrates (mica and alumina) and to partial or complete crack healing for densifying substrates (silica). A critical thickness for cracking could be discerned for these layers, which was about $100 \mathrm{~nm}$ for mica substrates and higher than $140 \mathrm{~nm}$ for the alumina and silica substrates. Surface steps in the mica are suggested to be responsible for this difference.

\section{Acknowledgements}

We thank O. Guillon and J. B. Ollagnier from the Technische Universität Darmstadt for the useful discussion and for the FEM simulation. We also thank the X-ray analyses at Merck KGaA,. K. Czerny (Merck KGaA, BET laboratory) and A. Kilian (Merck KGaA, SEM laboratory) for their technical help and A. Cismak of the Institute for Material Mechanics, Halle, Germany, for AFM measurements. 


\section{References}

1 G. Pfaff and P. Reynders, Angle-dependent optical effects deriving from submicron structures of films and pigments, Chem. Rev. 99 (1999), pp. 1963-1981.

2 J. Maile, G. Pfaff and P. Reynders, Effect pigments-past, present and future, Prog. Org. Coat. 54 (2005), pp. 150-163.

3 J. Zarzycki, M. Prassas and J. Phalippou, Synthesis of glasses from gels: the problem of monolithic gels, J. Mater. Sci. 17 (1982), pp. 3371-3379.

4 T. Mizuno, H. Nagata and S. Manabe, Attempts to avoid cracks during drying, J. Non-Cryst. Solids 100 (1988), pp. 236-240.

5 T.J. Garino and H.K. Bowen, Deposition and sintering of particle films on a rigid substrate, J. Am. Ceram. Soc. 70 (1987), pp. C315-C317.

6 T. Cheng and R. Raj, Flaw generation during constrained sintering of metal-glass multilayer films, J. Am. Ceram. Soc. 72 (1989), pp. 1649-1655.

7 A. Jagota and C.Y. Hui, Mechanics of sintering thin films-II cracking due to self-stress, Mech. Mater. 9 (1990), pp. 107-109.

8 G.W. Scherer, Theory of drying, J. Am. Ceram. Soc. 73 (1990), pp. 3-14.

9 R.C. Chiu, T.J. Garino and M.J. Cima, Drying of granular ceramic films: I effect of processing variables on cracking behavior, J. Am. Ceram. Soc. 76 (1993), pp. 2257-2264.

10 R.C. Chiu and M.J. Cima, Drying of granular ceramic films: II drying stress and saturation uniformity, J. Am. Ceram. Soc. 76 (1993), pp. 2769-2777.

11 R.K. Bordia and A. Jagota, Crack growth and damage in constrained sintering films, J. Am. Ceram. Soc. 76 (1993), pp. 2475-2485.

12 J.S. Reed, Principles of Ceramics Processing (2nd ed.), Wiley-VCH, Weinheim (1995).

13 M.N. Rahaman, Ceramics Processing and Sintering (2nd ed.), Marcel Dekker, New York (2003).

14 G.K.L. Goh, S.K. Donthu and P.K. Pallathadka, Cracking and orientation of solution-deposited rutile TiO2 films, Chem. Mater. 16 (2004), pp. 2857-2861.

15 M.S. Hu, M.D. Thouless and A.G. Evans, The decohesion of thin films from brittle substrates, Acta Metall. 36 (1988), pp. 1301-1307.

16 F. Zhao, B. Wang, X. Cui, N. Pan, H. Wang and J.G. Hou, Buckle delamination of textured TiO2 thin films on mica, Thin Solid Films 489 (2005), pp. 221-228.

17 Bauer, G., Osterried, K., Schmidt, C., Vogt, R., Kniess, H. B., Uhlig, M. et al., Coloured and 
coated platelike pigments. WO Patent 93/08237, 1991.

18 J.P. Jolivet, Metal Oxide Chemistry and Synthesis, Wiley-VCH, Weinheim (2000).

19 Y. Kuwahara, Muscovite surface structure imaged by fluid contact mode AFM, Phys. Chem. Miner. 26 (1999), pp. 198-205.

20 S. Teaney, G. Pfaff and K. Nitta, New effect pigments using innovative substrates Silica and alumina platelets extend the product variety and performance range of pearlescent pigments, Eur. Coat. J. 4 (1999), pp. 90-96.

21 G.V. Franks and L. Meagher, The isoelectric points of sapphire crystals and alpha-alumina powder, Colloids Surf. A 214 (2003), pp. 99-100.

22 D.M. Smith, G.W. Scherer and J.M. Anderson, Shrinkage during drying of silica gel, J. Non-Cryst. Solids 188 (1995), pp. 191-206.

23 G.W. Scherer, S. Hæreid, E. Nilsen and M.-A. Einarsrud, Shrinkage of silica gels aged in TEOS, J. Non-Cryst. Solids 202 (1996), pp. 42-52.

24 G.W. Scherer, Drying gels II film and flat plate, J. Non-Cryst. Solids 89 (1987), pp. 217-238. 25 G.W. Scherer, Drying gels VIII revision and review, J. Non-Cryst. 109 (1989), pp. 171-182. 26 M. Stech, P. Reynders and J. Rödel, Constrained film sintering of nanocrystalline TiO2, J. Am. Ceram. Soc. 83 (2000), pp. 1889-1896.

27 A.P. Legrand, The Surface Properties of Silicas, John Wiley \& Sons, New York (1998).

28 J. Rödel and A.M. Glaeser, High-temperature healing of lithographically introduced cracks in sapphire, J. Am. Ceram. Soc. 73 (1990), pp. 592-601.

29 J.M. Heintz, O. Sudre and F.F. Lange, Instability of polycrystalline bridges that span cracks in powder films densified on a substrate, J. Am. Ceram. Soc. 77 (1994), pp. 787-791.

30 F.F. Lange, Chemical solution routes to single-crystal thin films, Science 273 (1996), pp. 903909.

$31 \mathrm{H}$. Kozuka and M. Kajimura, Single-step dip coating of crack-free BaTiO3 films $>1 \mu \mathrm{m}$ thick: effect of poly(vinylpyrrolidone) on critical thickness, J. Am. Ceram. Soc. 83 (2000), pp. 1056-1062. 32 L.B. Freund and S. Suresh, Thin Film Materials. Stress Defect Formation and Surface Evolution, Cambridge University Press, Cambridge (2003).

33 M. Bockmeyer and P. Löbmann, Crack formation in TiO2 films prepared by sol-gel processing: quantification and characterization, Thin Solid Films 515 (2007), pp. 5212-5219. 
Figures

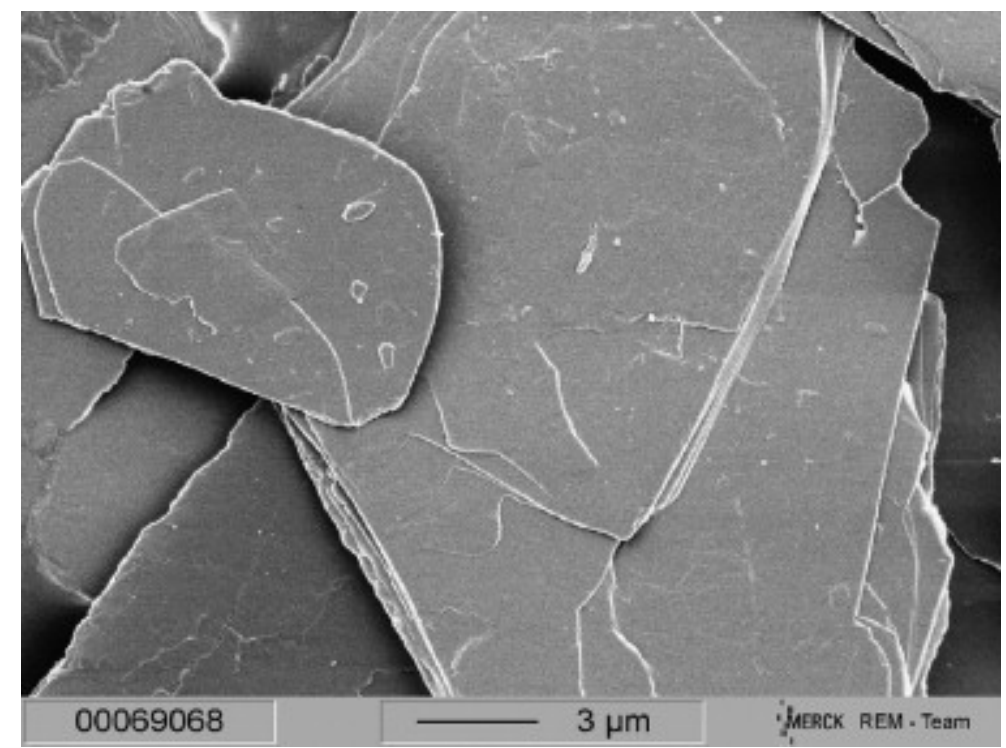

Fig. 1. SEM micrograph of mica substrates used in the LDP process.

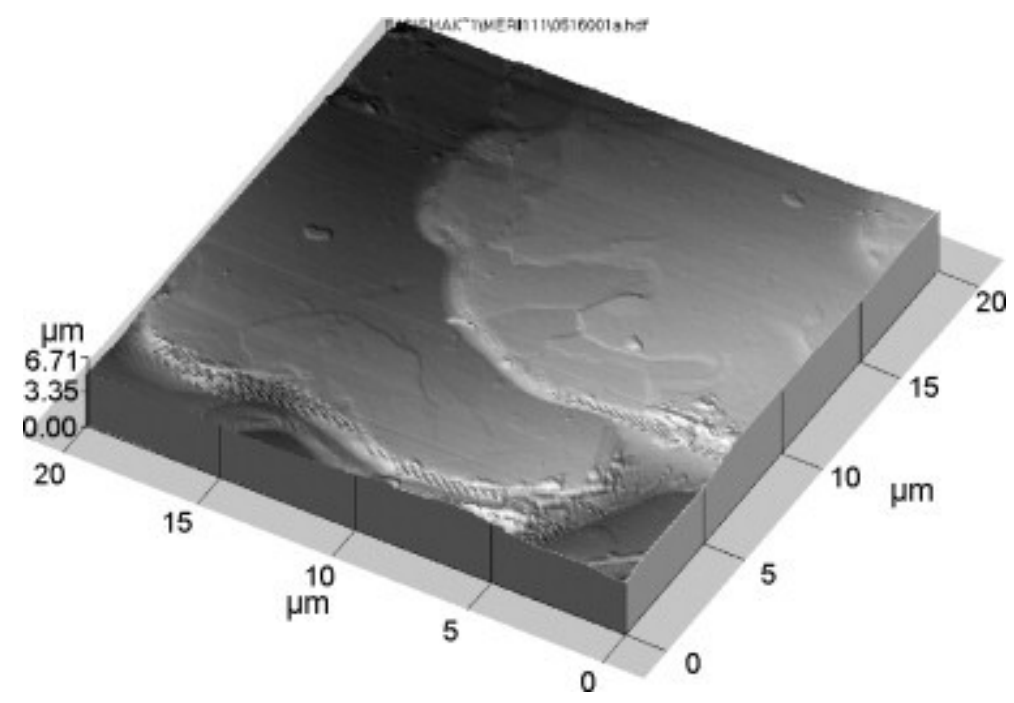

Fig. 2. AFM micrograph showing steps at the surface of natural mica. 
Merck KGaA / ICMCB / Technische Universität Darmstadt @ 2008

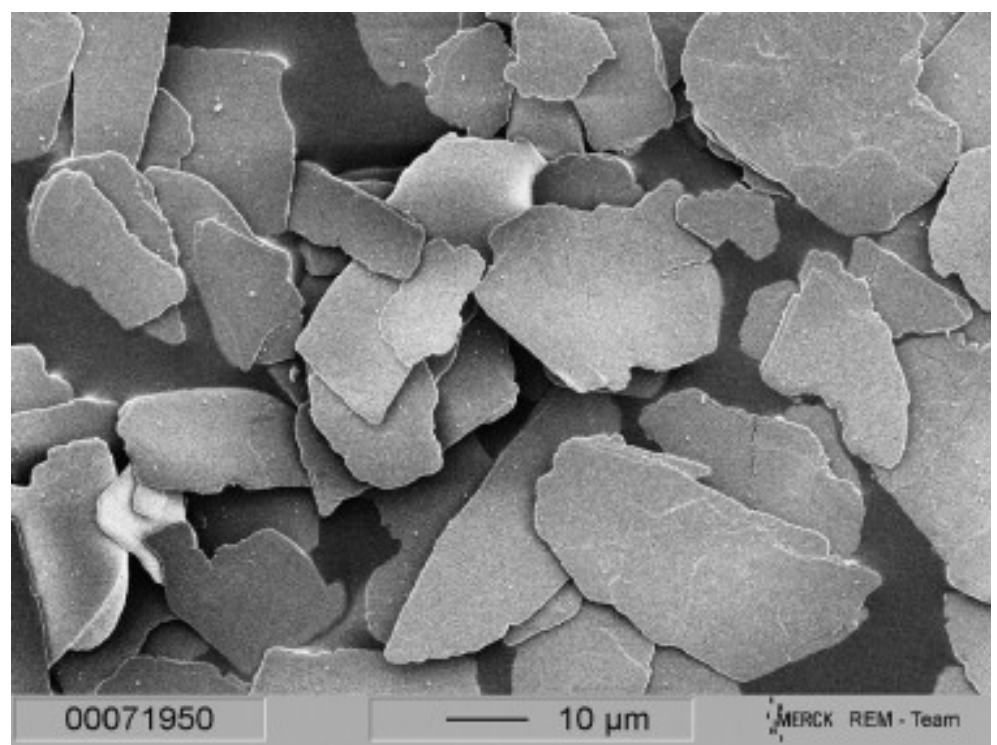

Fig. 3. SEM micrograph of Ti-140-mica pigment particles.
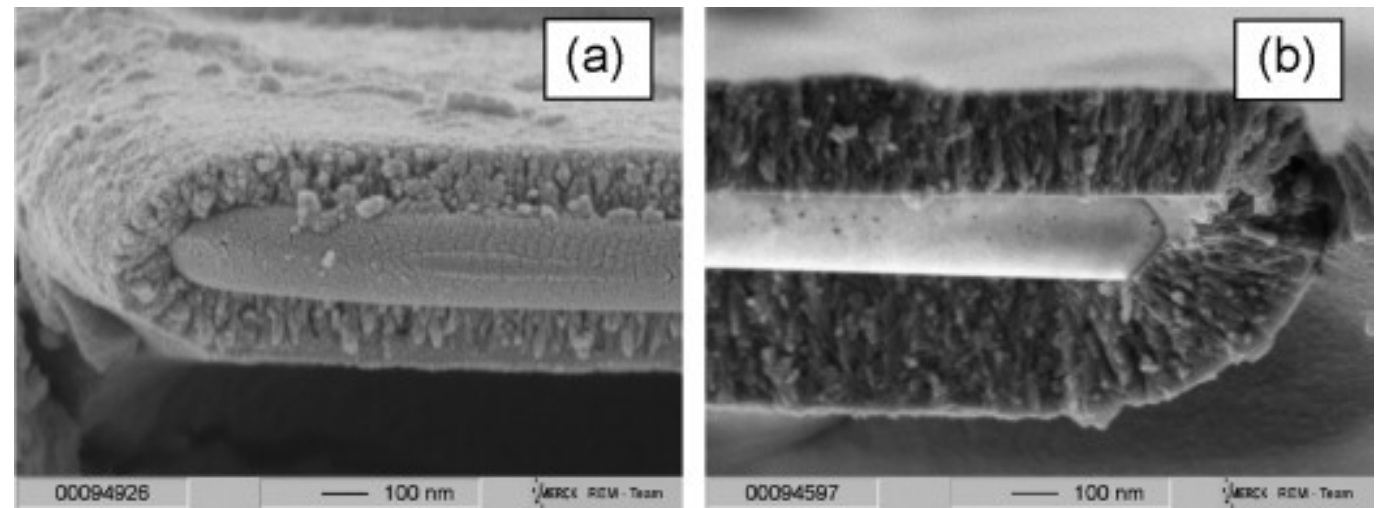

Fig. 4. SEM cross-section of dried pigment particles: (a) Ti-140- $\mathrm{Al}_{2} \mathrm{O}_{3}$; (b) Ti-300- $\mathrm{Al}_{2} \mathrm{O}_{3}$.
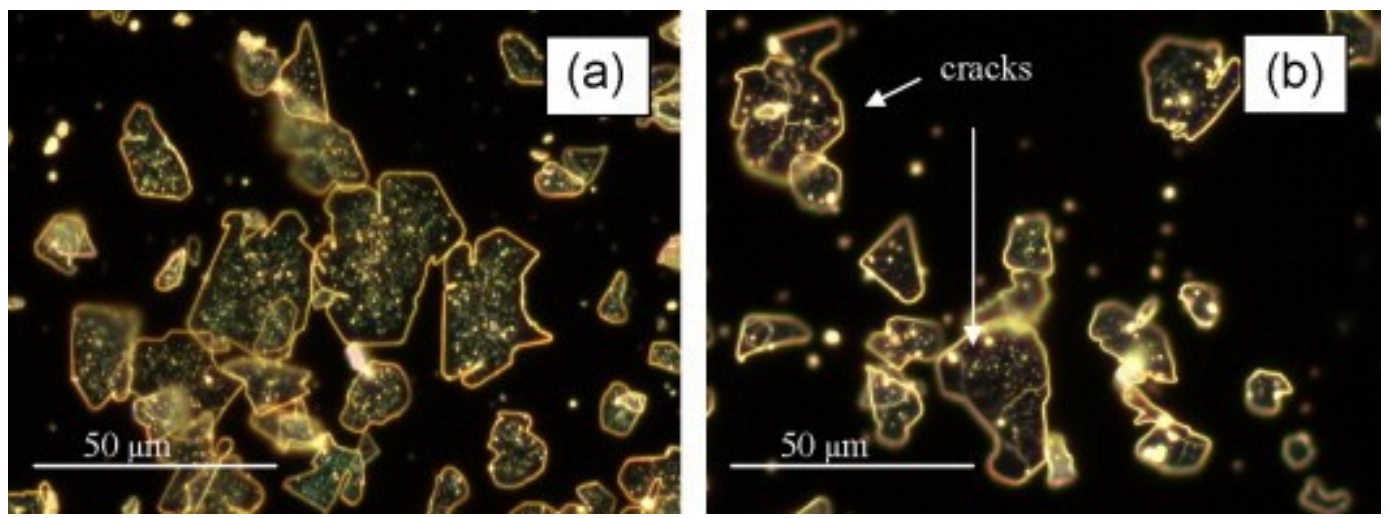

Fig. 5. Light microscopy images of (a) Ti-140- $\mathrm{Al}_{2} \mathrm{O}_{3}$ and (b) Ti-300- $\mathrm{Al}_{2} \mathrm{O}_{3}$ pigment particles in their dried state: no cracks were found in Ti-140- $-\mathrm{Al}_{2} \mathrm{O}_{3}$ whereas cracks can be detected in Ti-300- $\mathrm{Al}_{2} \mathrm{O}_{3}$. 
Merck KGaA / ICMCB / Technische Universität Darmstadt @ 2008
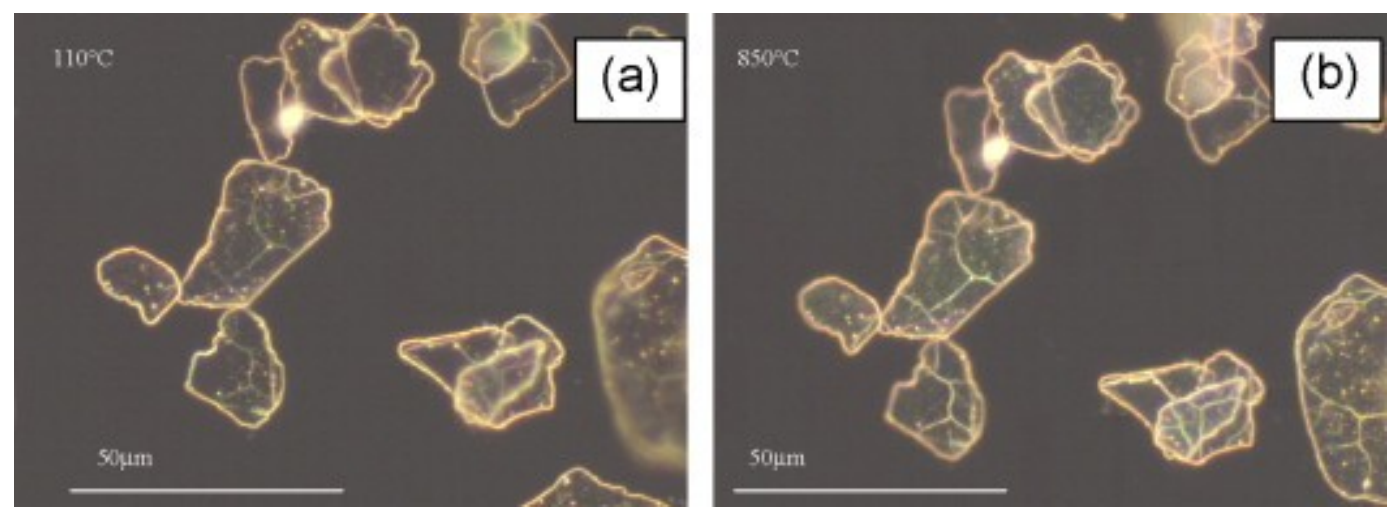

Fig. 6. Light microscopy images of Ti-140-mica pigment particles (a) before and (b) after sintering at $850^{\circ} \mathrm{C}$.
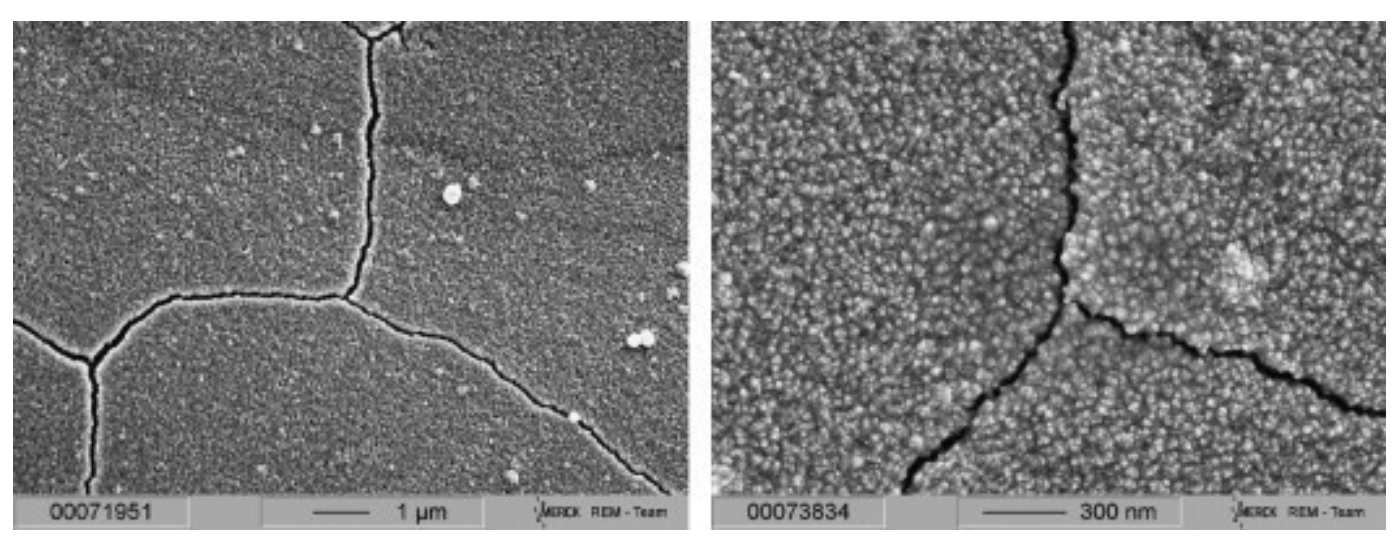

Fig. 7. SEM micrograph of a Ti-140-mica pigment particle (left) before and (right) after sintering at $850^{\circ} \mathrm{C}$.

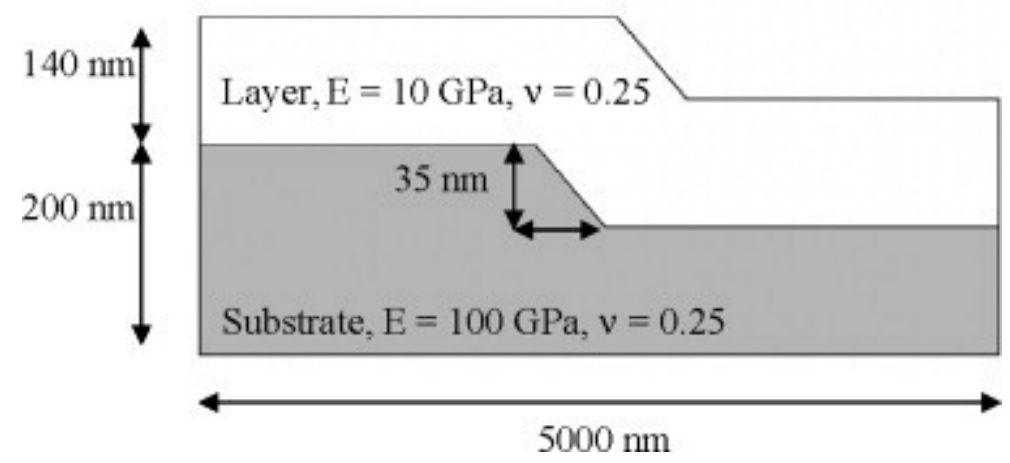

Fig. 8. Mechanical and geometrical parameters used in the FEM analysis $(\Delta T=100 \mathrm{~K}, *$ substrate $=9 \times 10^{-6} \mathrm{~K}^{-1}$, ${ }_{\text {layer }}=0.976 \times 10^{-6} \mathrm{~K}^{-1}$ ). 
Merck KGaA / ICMCB / Technische Universität Darmstadt @ 2008

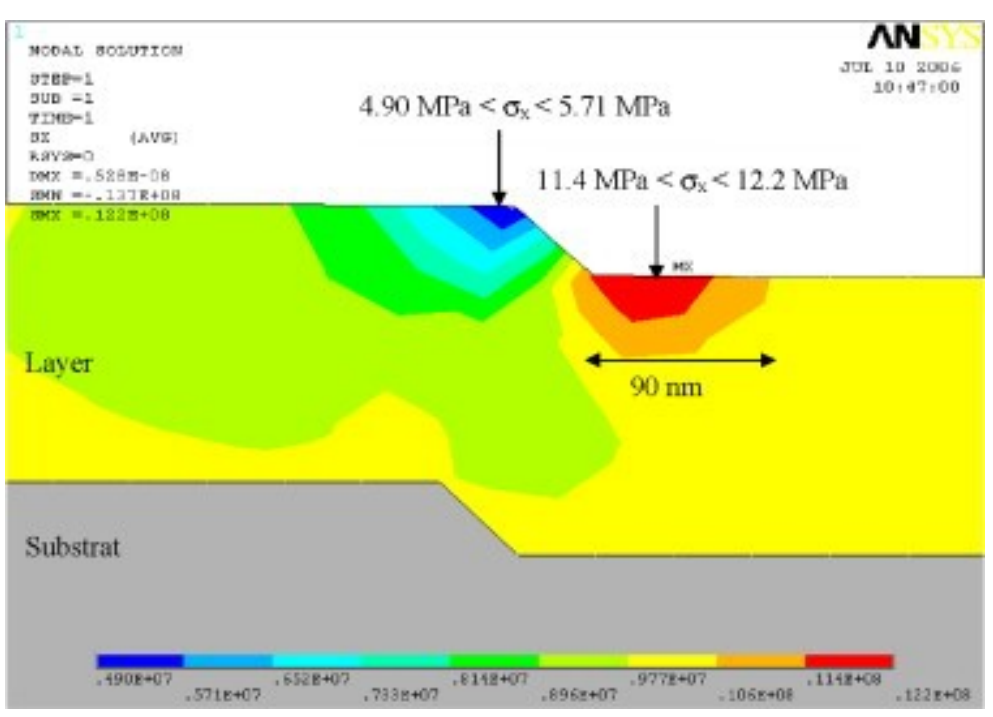

Fig. 9. FEM analysis: contour plot representing the stress distribution in a drying layer deposited on a substrate in the vicinity of a step-like defect. 
Table 1.

Volume shrinkage of $\mathrm{SiO}_{2}$ platelets deduced from pycnometry analyses

\section{$\mathrm{SiO}_{2}$ platelets $110{ }^{\circ} \mathrm{C} \quad \mathrm{SiO}_{2}$ platelets $600{ }^{\circ} \mathrm{C} \quad \mathrm{SiO}_{2}$ platelets $850{ }^{\circ} \mathrm{C}$}

\begin{tabular}{lccc}
\hline $\begin{array}{l}\text { Calculated density } \\
\left(\mathrm{g} / \mathrm{cm}^{3}\right)\end{array}$ & 1.736 & 1.770 & 2.019 \\
Volume shrinkage & Reference & $1.9 \%$ & $14 \%$ \\
\hline
\end{tabular}

Table 2.

Properties of dried $\mathrm{TiO}_{2}$ layers

\begin{tabular}{|c|c|c|c|}
\hline & $\bar{r}_{\mathrm{p}}(\mathbf{n m})$ & $G_{\mathrm{BET}}(\mathrm{nm})$ & 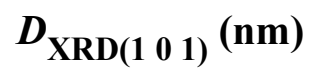 \\
\hline Ti-60-mica & 2.2 & 10 & - \\
\hline Ti-140-mica & 2.0 & 18 & 24 \\
\hline $\mathrm{Ti}-140-\mathrm{Al}_{2} \mathrm{O}_{3}$ & 2.6 & 26 & 21 \\
\hline Ti-140-SiO 2 & 2.1 & 18 & 22 \\
\hline $\mathrm{Ti}-300-\mathrm{Al}_{2} \mathrm{O}_{3}$ & 1.6 & 27 & 29 \\
\hline $\mathrm{Ti}-300-\mathrm{SiO}_{2}$ & 2.1 & 43 & 31 \\
\hline
\end{tabular}


Merck KGaA / ICMCB / Technische Universität Darmstadt @ 2008

Table 3.

Crack percentage in the different studied pigments (percentage of pigment particles exhibiting cracks in a sample)

\section{Samples and number of samples studied Crack percentage}

Ti-60-mica (3 samples)

Ti-140-mica (16 samples)

Ti-140- $\mathrm{Al}_{2} \mathrm{O}_{3}$ (5 samples)

Ti-140- $\mathrm{SiO}_{2}$ (5 samples)

Ti-300- $\mathrm{Al}_{2} \mathrm{O}_{3}(1$ sample $)$

Ti-300-SiO 2 (1 sample)
Low $(1-5 \%)$

High (30-40\%)

Very low $(1 \%)$

Very low (1\%)

High (20-30\%)

Moderate $(\sim 10 \%)$ but some delamination 